\title{
NATURAL CONVECTION IN TUNNELS \\ AT YUCCA MOUNTAIN AND IMPACT ON DRIFT SEEPAGE
}

\author{
N. Halecky ${ }^{1,2}$, J. Birkholzer ${ }^{2}$, P. Peterson ${ }^{1}$
}

${ }^{1}$ Department of Nuclear Engineering, University of California, Berkeley

${ }^{2}$ Lawrence Berkeley National Laboratory (LBNL)

\begin{abstract}
The decay heat from radioactive waste that is to be disposed in the once proposed geologic repository at Yucca Mountain (YM) will significantly influence the moisture conditions in the fractured rock near emplacement tunnels (drifts). Additionally, largescale convective cells will form in the open-air drifts and will serve as an important mechanism for the transport of vaporized pore water from the fractured rock in the drift center to the drift end. Such convective processes would also impact drift seepage, as evaporation could reduce the build up of liquid water at the tunnel wall. Characterizing and understanding these liquid water and vapor transport processes is critical for evaluating the performance of the repository, in terms of water-induced canister corrosion and subsequent radionuclide containment. To study such processes, we previously developed and applied an enhanced version of TOUGH2 ${ }^{1}$ that solves for natural convection in the drift. We then used the results from this previous study as a time-dependent boundary condition in a high-resolution seepage model, allowing for a
\end{abstract}


computationally efficient means for simulating these processes. The results from the seepage model show that cases with strong natural convection effects are expected to improve the performance of the repository, since smaller relative humidity values, with reduced local seepage, form a more desirable waste package environment.

\section{KEYWORDS}

Nuclear waste, seepage, TOUGH model 


\section{INTRODUCTION}

The unsaturated tuffs at Yucca Mountain, Nevada, were once considered as a geological repository for the disposal of high-level nuclear waste in the United States. Decay heat, from the emplaced spent nuclear fuel and defense wastes, would significantly alter the thermal hydrological (TH) conditions in the host rock and the waste emplacement tunnels. Pore water vaporization, transport and the subsequent condensation results in changes in water saturation and water/vapor fluxes throughout the surrounding rock. ${ }^{2}$ Characterizing and understanding these liquid water and vapor transport processes is critical for evaluating the performance of the repository, in terms of water-induced canister corrosion and subsequent radionuclide containment.

Previous computational fluid dynamic studies have shown the formation of large-scale natural convections cells along the length of the drifts, a result of temperature differences between the heated and cool sections of the drift. ${ }^{3}$ These convective cells could provide an effective mechanism for moisture transport of pore water, evaporated from the rock formation, from the heated drift centers to the cool drift ends (where no waste is emplaced). To understand these processes, a new module was developed for TOUGH2 ${ }^{1}$, a general-purpose simulator for coupled fluid and heat flow of multi-phase, multicomponent fluid mixtures in porous and fractured media, allowing the solving of natural convection processes in open cavities. The new module simultaneously handles (a) the flow and energy transport processes in the unsaturated fractured rock, (b) the flow and energy transport processes in the cavity, and (c) the heat and mass exchange at the rockcavity interface. 
Recent studies employed TOUGH2 with the new module to simulate the impact of natural convection on the future TH conditions of a full 3D drift domain, including the indrift environment and the surrounding fractured rock ${ }^{4,5}$. Results from these studies showed a large increase in the moisture transport away from the heated drift center toward the cooler drift ends for the time period that thermal perturbation from decay heat prevails, and a subsequent reduction in the relative humidity $(\mathrm{RH})$ of the in-drift environment, suggesting a substantial increase in the evaporative potential at the drift wall when compared to a case with no natural convection.

In this paper, we present a new procedure for investigating the complex coupled behavior between natural convection and its impact on drift seepage. In the context of the Yucca Mountain repository, seepage refers to the flow of liquid water into open emplacement drifts, or simply the dripping of liquid water from the tunnel walls, as shown in Figure 1. Previous studies investigating thermally driven flow processes and their impact on seepage neglected the presence of open drifts as conduits for gas and vapor transport along the drift axis ${ }^{2}$, thus neglecting an important mechanism for seepage reduction. To better understand what role the natural convective processes might have on minimizing seepage of percolation water into the tunnels, we developed a high-resolution seepage model based on existing seepage models; however, now additionally employing the new natural convection module. Because an increased grid resolution was needed to allow for heterogeneity in element permeability near the drift wall, computational limitations prevented simulation of an entire drift in the new model. Instead, we used the time 
dependent in-drift response from the previous full-drift and rock model (temperature, pressure, and relative humidity) as a Dirichlet boundary source for a short drift section represented in a high-resolution seepage model. To account for future variations in subsurface flow expected at Yucca Mountain, the simulation time period of 5,000 years after emplacement covers three expected climate stages, with present-day climate up to 600 years in the future, followed by a wetter monsoon climate up to 2,000 years, and an even wetter glacial transition climate thereafter. Climate periods are implemented into the model in the terms of stepwise increases in net surface infiltration rates.

\section{PHYSICAL PROCESSES}

\section{Natural Convection Processes}

Vapor entering the emplacement drifts from the fractured porous rock is subject to effective radial and axial mixing transport as a result of natural convection processes. Axial mixing can reduce the overall moisture content in heated drift sections because of the presence of the unheated drift ends (turnouts). Principles of thermodynamics suggest that the maximum amount of vapor that can be present in air decreases with declining temperature. Thus, the warm vapor-rich gases moving from heated drift sections toward the drift turnouts—caused by natural convection processes—will be depleted of most of their vapor content through condensation on cooler rock surfaces. The condensate will then drain away from the repository into underlying rock units. At the same time, vaporpoor gas will circulate back towards the center of the drift (where the waste is emplaced), thereby reducing the moisture content of the air mixture in these areas ${ }^{4}$. 


\section{Seepage Processes}

Of the modest amount of precipitation in the Yucca Mountain region $(\sim 170 \mathrm{~mm} / \mathrm{yr})^{6}$, a small portion of it infiltrates into the ground surface (on average about 5-6 mm/yr at current climate conditions) above the repository ${ }^{7}$, percolates downward through the unsaturated porous rock, through both fracture and matrix domains and eventually reaches the drift wall. Under the flow and thermodynamic conditions expected at Yucca Mountain, the major fraction of this percolation water does not seep, but is rather diverted around the drift opening due to many seepage barriers (described below) present in the surrounding rock. Still possible are physical processes, occurring outside of those expected, which might create conditions allowing seepage to occur. What these processes are and how they might impact seepage is the focus of discussion that follows.

\section{Ambient Seepage}

Ambient seepage refers to the amount of seepage occurring during non-heated conditions, representing the long-term situation at Yucca Mountain when the initial perturbation from decay heat has ceased. As such, ambient seepage serves as a baseline to compare model response during the thermally perturbed time period. Parameters that have the largest impact on seepage at ambient temperatures are:

- the amount of percolation flux above the drifts (amount of water arriving at the drift wall), including effects of preferential flow which could increase percolation in certain drift sections

- the local heterogeneity of the fracture flow field (the spatial variability of fracture permeability close to the drift opening), 
- and the capillary strength of the fractures close to the wall (defining the amount of water the rock can hold) ${ }^{8}$.

\section{Thermal Seepage}

Thermal seepage refers to seepage during the time period that the flow around drifts is perturbed from heating due to radioactive decay. Heating of the rock creates additional temperature-driven physical processes that play a role in redistribution of water in the surrounding rock. Then, to consider a repository scenario with thermal seepage, we must investigate all possible impacts on seepage, both processes that increase or reduce the amount of liquid water from existing at the drift wall and/or from seeping into the drifts. It is important to consider that while water might be redistributed, it is not removed from the system. We considered three barriers—processes that remove or reduce liquid water-for the study.

Vaporization Barrier: First, the vaporization barrier occurs when the surrounding rock is above boiling temperatures, forming a superheated dryout zone around the drifts as shown in Figure 2. This serves as a barrier to seepage as all percolating liquid water is vaporized prior to reaching the drift wall. It has been shown that the flow of percolation water is diverted around these dryout regions, into a below-boiling zone existing between two drifts. The vaporization barrier serves as the sole barrier to seepage until rock temperatures return to below boiling, establishing thermodynamic conditions at which liquid water can exist at the drift wall. It is at this stage that the rock properties at the drift wall impact the likelihood of seepage. 
Capillary Barrier: Water tends to divert around underground openings because of capillarity, a phenomenon well known as the capillary barrier. Indeed, this phenomenon is explored by many inquisitive minds with the investigation of the wetting of a dry kitchen sponge by a small flow of water. It is observed that there will be no dripping from the underside of the sponge until a region forms there that has been completely wettedreducing the capacity for the pore spaces within the sponge to hold any additional water. In unsaturated zone transport, a similar condition arises, for example, when coarsegrained soils are overlain by fine-grained soils.

What is the mechanism driving this phenomena? Adhesive forces between water and the rock grain surface drive water to cover and hold to these surfaces, creating a potential against the force of gravity. In general, the fine-grained material exhibits stronger capillarity because the ratio of the pore surface area to total material volume is much larger than in the coarse-grain material. With a larger surface area over which the water adheres to per unit volume, the fine-grained material more forcefully holds to liquid water stored in its pore structures.

Across this boundary between the two mediums, the stronger negative capillary pressure developed in the fine-grained material prevents water from entering the larger pores of the underlying coarse-grained material ${ }^{8}$. In this scenario, the capillary barrier can only be overcome by decreasing capillary pressure in the small-grained material so that it is equal to or less than that of the coarse-grained material. This can only occur by increasing the saturation in the fine-grained material, so that, with the loss of pore space to hold 
additional water, the adhesive forces also decrease and, in turn, reduce the capillary pressure. In the limit-approaching case of infinite pore size (such as an open tunnel), seepage into the drift can only occur if the capillary pressure in the rock nearby the drift walls becomes zero- the case when the rock has reached saturation.

In this context, one must consider the large differences in capillarity between the fracture and matrix continua (the matrix having a much stronger capillarity due to its small pore size) in the fractured porous rock at Yucca Mountain. This difference means that the matrix will strongly imbibe liquid water from fractures, and must be nearly saturated (reducing the capillary pressure of the matrix), before any significant buildup of liquid water can occur in the fractures. However, even with the matrix being close to saturated, seepage is only expected to occur from the fracture domain. This is because the capillarity of the saturated matrix is still significantly stronger than that of the fractures.

Additionally, an increase in the local saturation in the rock can occur due to a disturbance to the flow field (caused by the presence of the drift opening) and more importantly by spatial heterogeneity that promotes channelized flow and local ponding ${ }^{8}$. (Here, ponding refers to a scenario with a local region of rock being fully saturated in an otherwise unsaturated medium.) Variations in fracture permeability along the drift wall allow for regions of increased (or decreased) local saturation, along with changes in the flux of liquid water along the drift wall—creating conditions possibly beneficial for seepage.

Evaporation Barrier: Finally, evaporation of water at the drift wall, enhanced by natural convection transport, would also serve as a barrier in limiting seepage. Liquid 
water accumulating at the drift-wall surface, which might overcome the capillary barrier and seep, would be subject to removal by evaporation and be transported via natural convection down the tunnel to be condensed in the cooler regions in the drift end. Although the vaporization and capillary barrier have been explored in great detail in previous studies $^{2,13}$, the effect of an evaporation barrier has not yet been considered in seepage modeling studies.

The magnitude of this evaporation process and its role in seepage reduction is the focus of this research effort. This, combined with the previous two barrier systems, will provide a better understanding of how natural convection and the subsequent vapor transport in the axial direction might further reduce the likelihood of seepage at the Yucca Mountain repository.

\section{MODELING APPROACH}

During times with thermal perturbations due to decay heat, the in-drift environment is impacted by axial vapor transport via natural convection. These processes occur over the length of the entire drift and, therefore, require the modeling of a full-scale drift tunnel (including drift turnout, where no waste is emplaced) along with the surrounding host rock.

Developing a model that captures and solves both seepage and natural convection processes simultaneously would require an extremely complex discretization and significant computational resources. Instead we utilize a unique method that involves two 
models of different spatial scale. The first model is our previously developed natural convection model for the full drift and the surrounding rock ${ }^{4}$ (referred from here on as the nat-co model), which simulates the time-varying thermodynamic response of the full indrift domain. The second model is a high-resolution seepage model covering a much shorter drift section, which specifically deals with smaller-scale seepage-relevant processes (referred from here on as the seepage model). The seepage model uses results from the nat-co model as a time-dependent boundary condition (temperature, pressure, and relative humidity) for the in-drift domain. By implementing this time-dependent response, we are then not required to model the entire length of the drift in the seepage model, a significant advantage as it reduces the grid complexity by an order of magnitude. Because these time-dependent in-drift boundary conditions-generated from the nat-co model — will have a large impact on seepage, we shall summarize important aspects of this model and follow with details of the seepage model.

\section{Nat-Co Model: The Previous Full-Drift And Rock Natural Convection Model}

We performed three-dimensional simulation runs for a representative emplacement drift chosen in one of the southern panels of the repository (Figure 3$)^{4}$. In the vertical direction ( $\mathrm{z}$ direction), the model comprises the entire unsaturated zone, using the ground surface as the upper model boundary and the groundwater table as the lower model boundary. We used two symmetry assumptions to increase the computational efficiency of the simulation runs. In axial drift direction (y-direction), symmetry allows for reducing the model to half of the drift length (plus sufficient volumes of fractured rock beyond the end of the drift to provide adequate boundary conditions). Thus, the simulated drift comprises 
half of the typical emplacement section length $(300 \mathrm{~m})$ followed by an unheated section away from the symmetry axis, here assumed to be $90 \mathrm{~m}$ long. Following the grid design developed by Spycher et al. ${ }^{9}$, symmetry assumptions also allow to reduce the model domain in the $\mathrm{x}$ direction, perpendicular to the drift axis. The current repository design of parallel drifts is then be represented as a series of symmetrical, identical half-drift domains with vertical no-flow boundaries between them. Thus, the numerical mesh can be reduced to a lateral width of $40.5 \mathrm{~m}$, extending from the drift center to the midpoint between drifts. We further simplified the model geometry by neglecting the curvature of the drift turnout and by assuming strictly horizontal top and bottom model boundaries.

The numerical grid used in the simulations is shown in Figure 3 on a vertical cross section orthogonal to the drift axis. In this cross section, the drift domain comprises one finite volume for the waste package (for the lumped waste package, air gap, and drip shield unit), one finite volume for the invert (the flat base of the drifts), and 18 finite volumes for the annulus. Based on the dual-continuum concept, there are two overlapping continua for the fractures and the matrix blocks, respectively, with identical discretizations, to account for their strongly differing rock properties. ${ }^{2}$ In the third dimension (along the drift axis), the numerical grid comprises 28 vertical slices of varying thickness, ranging from $5 \mathrm{~m}$ to more than $100 \mathrm{~m}$. The entire three-dimensional grid comprises about 10,000 finite volumes with about 35,000 connections between them.

To approximate the effects of natural convection, we followed the methodology described in Webb and Reed ${ }^{3}$, and assumed that the axial transport of vapor and air can 
be simplified as a binary diffusion process of the air-vapor mixture, using effective mass dispersion coefficients calculated from complementary computational fluid dynamics (CFD) flow field simulations. By approximating natural convection as a binary diffusion process, the in-drift heat and fluid flow processes can, in principle, be simulated with the standard methodologies applied for Darcy-type flow and transport (such as those implemented in TOUGH2), with the drift represented as a specific solution sub-domain that requires certain code modifications and parameter specifications.

Additionally, we employed empirical boundary-layer correlations to calculate the heat transfer between the open drift and the confining bodies as a function of heat-transfer coefficients and the local temperature gradient. Diffusive mass transfer was calculated from similar correlations, using an empirical mass-transfer coefficient and the local vapor concentration gradient ${ }^{10}$. This calculation is conducted for heat transfer between the waste package and the open drift, for heat and mass transfer between the open drift and rock mass (for both fracture and matrix continua), and for heat and mass transfer between the open drift and the invert. We developed a new drift simulation version of TOUGH2 that solves simultaneously for heat and fluid flow within the drift and in the surrounding rock mass ${ }^{11,5}$.

We ran the nat-co model for a time period of 5,000 years considering three convective mixing cases, as shown in Table 1, with the effective mass dispersion values based off of results from a previous CFD model investigating the magnitude of natural convective mixing $^{5,12}$. Cases 1 and 2 represent the variability and uncertainty about the magnitude of 
convective mixing; Case 3 is a comparison case, where convective mixing is ignored (and thus binary diffusion is the only contribution to the effective mass dispersion coefficient). As shown in Figure 4, Case 1 (strong convective mixing) causes considerable transport of vapor from heated drift sections to the unheated end, and gives rise to reduced relative humidity along the length of the drift when compared to the case with moderate and no convective transport. It is this time-varying response (temperature, pressure, and $\mathrm{RH}$ ) that will serve as a boundary condition input for the seepage model. We expect that the evaporative potential associated with the strong convective mixing case will increase the transfer of moisture from the fractured rock mass into the drifts and thus may reduce seepage at the drift wall.

\section{Seepage Model: High-Resolution Model for Seepage Processes}

When considering the impact of natural convection, we can assume that the in-drift is well-mixed, or that there is no significant change in the local thermodynamic conditions of the in-drift domain nearby a seepage event. We consider this by developing a quasi-3D model, with boundary conditions prescribed in the same manner as the nat-co model. The high-resolution seepage model, based on existing TH seepage models ${ }^{13}$, employs all the same framework as the nat-co model explained above, but with additional modeling details as follows.

\section{Modeling Framework for Fractured Rock Mass}

The model extends from the mountain surface to the water table, yet has a more finely gridded mesh in the $\mathrm{x}-\mathrm{z}$ plane (Figure 5), allowing for prescribing a heterogeneous 
fracture permeability field to a region of rock extending 20 meters from the drift wall (fracture permeability was constant in the nat-co model). Additionally, the mesh includes variation in the geologic strata representing varying rock properties from borehole samples ${ }^{14}$. The drift vicinity in this model resides in the Topopah Spring Tuff lower lithophysal geologic unit, chosen as a majority of the repository resides within this type of geologic layer.

Instead of including the entire length of the drift in the model (as was done in the previous nat-co model), it now incorporates only a 25 meter long section of the drift, divided into nine vertical layers (Figure 6). Still with these simplifications, the grid contains about 17,000 grid blocks and 70,000 connections, considerably more than in the previous nat-co model. To accommodate this additional amount of calculations, we used a parallelized version of the TOUGH2 code $^{15}$ allowing calculations to be performed over computer clusters, greatly reducing simulation times.

Birkholzer et al. ${ }^{13}$ generated multiple realizations of a heterogeneous fracture permeability field using a stochastic method, with spatial variability based on small-scale air injection tests conducted in the underground test tunnel at Yucca Mountain. The specific realization selected for the fracture permeability field contains a highly permeable region next to a low-permeability region at the rock-drift interface—a scenario promoting seepage as it allows for local ponding at the wall. It is this region of elements (represented in Figure 6) that will be observed in greater detail. 
Another main component of seepage modeling is the implementation of a small capillarystrength parameter for the fracture continuum in the drift vicinity. This parameter relates the fracture saturation to the capillary pressure; it was derived in previous work ${ }^{16}$ from inverse modeling and calibration to niche liquid-release tests conducted at Yucca Mountain. This calibrated parameter incorporates not just the physical capillarity of the fracture network surrounding the tunnels, but also potential effects from permeability changes due to excavation effects, small-scale wall roughness, high-frequency episodicity from small-scale flow processes, film flow, drop formation, discrete fractures that may terminate at the wall, artifacts of finite discretization, and, effects from lithophysal cavities. The magnitude of the capillary strength parameter affects the possibility of seepage from occurring-a smaller value promotes seepage while a larger value reduces seepage. As explained previously, seepage from the rock matrix is not expected because of the very strong capillarity existing in that domain. Other rock properties, including soil-moisture characteristic curves and thermal characteristics, are listed in Table 2.

\section{Modeling Framework for Capillary Barrier Behavior at the Drift Wall}

A key element for seepage modeling is the specific seepage boundary condition implemented for the fracture continuum at the rock-drift interface. In the model, we represent drifts as open cavities with a zero capillary-strength parameter. For a vertical connection between the fracture continuum at the drift crown and the drift, downward seepage occurs when the threshold capillary pressure at the last node adjacent to the opening exceeds (is less negative than) a value of $-\rho g \Delta z$, where $\rho$ is density, $g$ is gravitational acceleration, and $\Delta z$ denotes the distance between the last formation node 
and the first drift node, the latter placed inside the drift immediately at the rock-drift interface. According to this relationship, the fracture continuum close to the drift wall does not need to be fully saturated for seepage to commence. For the properties used in this simulation, seepage conditions exist when the fracture saturation near the wall exceeds about 0.5 . Also, the threshold pressure for seepage increases slightly (becomes less negative) with elevated temperatures because of liquid density changes. Therefore, at higher temperatures, the threshold saturation for seepage may be slightly higher than 0.5 .

Conceptually, setting a non-zero nodal distance $\Delta z$ at the rock-drift interface accounts for the possible presence of discrete fracture segments intersected by the drift opening. If these segments do not extend far enough laterally or do not have a lateral connection to other fractures, the water carried in these segments cannot bypass the opening. As a result, the probability for seepage would increase beyond the value expected for a porous formation, depending on whether the gravity-driven flow in the discrete fracture segment can overcome the capillary barrier. Finsterle et al. ${ }^{16}$ propose to use a value of $0.05 \mathrm{~m}$ as representative for the fracture geometry observed in drifts at Yucca Mountain.

Before dripping, liquid water that overcomes the capillary barrier at the drift wall is likely to form a film over the local surface of the wall, which was demonstrated in seepage field experiments conducted at Yucca Mountain ${ }^{17}$. The question whether a liquid film forms or not as fracture flow approaches the drift wall is quite relevant in this paper because it heavily influences the area available for evaporative drying. If a liquid film forms, evaporation occurs over the locally wet area of the drift wall. If not, evaporation can only 
occur over the small cross-sectional area where the flowing fracture intersects the drift. The model results described in this paper are based on the assumption that film evaporation occurs at the drift wall, and that the area available for such film evaporation is proportional to the fracture saturation and the drift wall surface of the seeping gridblock. However, we note that we have performed alternative simulation cases assuming that no liquid film forms. In these cases, evaporative drying is almost negligible, independent of the relative humidity conditions in the drifts.

\section{Model Boundary Conditions}

Seepage is a local event, and occurs over regions of rock on the order of less than a meter. While the in-drift thermodynamic conditions are dependent on the amount of percolation water evaporated into the drift (during sub-boiling conditions), the additional amount of water arriving due to a seepage event is small when compared to the total amount of water arriving and evaporating over the length of the drift.

Seepage is most likely to occur in drift regions where the local percolation flux is much higher than the average percolation, a possible result of intermediate-scale heterogeneity leading to flow focusing. To account for the possibility of locally higher flux arriving at a drift region, we consider three flow focusing cases by multiplying the average input percolation flux prescribed at the model upper boundary by factors of 1, 10 and 20 (Table 3). These three cases are referred to as no flow focusing, flow focusing 10, and flow focusing 20 cases, respectively. We restrict the flux increase to a thin $(0.25 \mathrm{~m})$ vertical layer in the model, preventing any transport of liquid between this layer and the adjacent 
layer (Figure 6) while still allowing heat transfer in the axial direction. It is this layer of locally focused flux, and the region with increased fracture permeability along the drift wall, that is significant to this study.

\section{MODEL RESULTS}

The goal of this study is to evaluate the potential impact that natural convection has on drift seepage, which is largely affected by the local in-drift thermodynamic conditions at the drift wall in a seepage-prone region. All model results presented below are from the vertical layer of locally focused flow, where average percolation rates have been adjusted by flow focusing factors of 1,10 , and 20 , respectively.

\section{Temperature}

First, we will look at temperature response at the drift wall from 50 to 5000 years, the time scale for all future plots. We show in Figure 7 the temperature response in the most seepage prone element (that having the largest local saturation buildup) at the drift wall, represented by the thick lines and also the temperature of the time-dependant in-drift Dirichlet boundary condition, represented by the thin lines (only in Figure 7.c). Temperatures max out around $150^{\circ} \mathrm{C}$ shortly after emplacement of waste, then cool to the boiling temperature $\left(96^{\circ} \mathrm{C}\right)$ around year 800 , and eventually drop to below $60^{\circ} \mathrm{C}$ by year 5000. Similar behaviors are observed in all flow focusing cases, with slightly lower temperatures in the flow focusing 20 case due to the increase in the percolation flux. It is however noted that the temperatures are hardly affected by variations in flow-focusing, testament to the effective transfer of heat from the waste packages to the seepage wall 
location via thermal radiation and also heat conduction through the rock from the adjacent vertical layers. This is consistent with our assumption that seepage would occur over a very small region of the drift, and as such, have little impact on the local temperatures.

The parameter having the largest impact on the temperature is the magnitude of

convective mixing. In previous studies ${ }^{4,5,11}$, we observed the temperature of the seepage element for the strong convective mixing case being lower than that for the other two convective mixing cases. Again, this is due to the more effective heat removal from the drift center due to enhanced axial vapor transport in the strong convective mixing case.

\section{Matrix Saturation}

As discussed previously, saturations in the rock matrix do not directly correspond to an understanding of seepage due to the large difference in the capillarity between the two continua. They do, however, provide an insight into when the fractures are able to resaturate (the saturation of the fractures create conditions for seepage) and also provide an understanding of vapor transport between the rock wall and in-drift (discussed later). We depict in Figure 8 matrix saturation in the seepage-prone element for the varying flow-focusing cases. In these plots, the transitions between current and future climate stages are distinguished by vertical grey lines on the plot.

For the no flow focusing scenario (Figure 8.a), resaturation does not occur in the case of no convective mixing until around year 340. Similarly, the moderate convective mixing 
case sees initial resaturation occurring around year 400. Interestingly, both these times correspond to temperatures well above the boiling point, at $107^{\circ} \mathrm{C}$ and $110^{\circ} \mathrm{C}$, respectively. The strong capillarity in the hot desaturated matrix competes with the boiling point of water at this depth, increasing it, allowing a small presence of liquid water to exist in the matrix pores at such high temperatures. The strong convective mixing case does not see resaturation occur until much later, around year 700 (corresponding to a temperature of $94^{\circ} \mathrm{C}$ ), a result of the effective drying of the rock wall from the low relative humidity of the in-drift environment. This drying is further exemplified when observing the magnitude of saturation achieved in the various convective mixing cases, with the strong convective mixing (dashed line) resulting in a much lower matrix saturation than in the cases with no or moderate convective mixing. This is apparent across all flow-focusing scenarios, and is a result of the ability for natural convection to reduce the relative humidity in the air, and remove moisture from the surrounding rock.

For the starting times of resaturation in the strong convective mixing case (dashed line) for the other flow focusing scenarios (Figures 8.a, 8.b), one can see that the years when it begins are practically the same across all flow-focusing cases-around year 700. This also occurs in the moderate and no convective mixing cases, with resaturation times for all flow focusing scenarios occurring at years 340 and 400, respectively. These results show that the starting time of resaturation of the matrix is affected little by variation in the rate of percolation, consistent with findings in the temperature response (which also is little affected by the percolation). In fact, as saturation in the rock is primarily dependant on the rock temperature, we are observing the same times for matrix resaturation because 
the temperatures in the rock remain the same across the three flow focusing cases. So then, for any given convective mixing case, the time of matrix resaturation is more or less the same.

Tracing the evolution of saturation in the no and moderate convective mixing cases (Figure 8, dash-dotted and solid lines), we see a jump occurring at year 600, corresponding to the assumed future transition from a present-day to a wetter monsoon climate. Eventually both convective mixing cases converge to a threshold saturation around 0.99 . Also, the rate at which saturation occurs is impacted by the percolation rate, evident by observing the slope of saturation in the no convective mixing and moderate convective mixing cases (dash-dotted and solid lines) just after year 600, all of which have a notable increase with increasing percolation. For the strong convective mixing case (dashed line), we see greater variation in the response across the flow-focusing cases, with much lower saturation overall. Strong convective mixing greatly reduces moisture in the rock for all flow-focusing cases. 


\section{Fracture Saturation}

More important to predicting thermal seepage is the fracture saturation in the seepage element. We show in Figure 9 fracture saturations for each flow focusing case and each convective mixing case. The fractures are completely dry in all cases for the first 800 years as the rock temperature during this time remains above boiling preventing liquid water from existing in the fracture voids. As the decay heat diminishes and the matrix has partially saturated, rewetting occurs soon thereafter in the no convective mixing (dashdotted line) and moderate convective mixing (solid line) cases, around year 900 for both. Discussed above, the beginning of the fracture resaturation corresponds to a certain saturation being reached in the matrix when the capillary pressure is reduced significantly to allow water to exist in the fractures. Water present in the fractures provides another source for matrix saturation (i.e., water imbibes into the matrix due to capillary forces), as compared to the case earlier in time, where only the matrix domain was transporting water. As such, these times correspond to an increase in matrix saturation, apparent with the increase in the slope of saturation a few years after the change to a wetter climate and higher infiltration rates at year 600 .

As we would expect, the increase in the infiltration rate at year 2000, due to another assumed climate transition to glacial climate, promotes a jump in the fracture saturations, which slowly increase with time after (a result of declining temperature). For the no flow focusing case combined with the strong convective mixing case (solid line in Figure 9.a), no water is observed near the drift wall until well after 3000 years, showing the evaporative potential of the strong natural convection processes. A similar behavior is 
observed for the flow focusing 10 case, depicted in Figure 9.b, however now with much larger fracture saturations and earlier rewetting of the fractured rock. Whereas fracture saturations in the no flow focusing case approach 0.2, the fracture saturations are now close to 0.5 . Also, we see the rewetting of the seepage element in the strong convective mixing case much earlier, around year 1200.

The flow focusing 20 case (Figure 9.c) shows an even larger response in fracture saturation for all convective mixing cases due to the increase of the percolation rate. In this case we now observe the saturation reaching a threshold, when the slope becomes zero-around 0.5 for all cases. For both the no convective mixing and moderate convective mixing cases, this occurs around year 2000 due to the transition from monsoon to glacial climates and the subsequent increase in the infiltration rate boundary condition by a factor of about 1.5. The strong convective mixing case reaches critical saturation much later, around year 3300, meaning evaporation at this case effectively delays the element from reaching a critical saturation until the thermodynamic conditions of the indrift become such that it can happen. It is at these critical values where we can expect seepage to occur.

\section{Seepage Percentage}

We check our predictions by observing the seepage percentage, both ambient and thermal, from a seepage-prone element. The seepage percentage is defined as the ratio of the liquid flux that seeps into the drift to the total liquid flux percolating with constant infiltration rate through a cross-sectional area corresponding to the footprint of the drift. 
The calculation is done only for the vertical layer of locally focused percolation flux. As expected from the fracture saturation plots, for the time periods plotted no seepage was observed in the flow focusing 10 and no flow focusing cases, as the threshold saturation was never reached. Therefore, we show in Figure 10 seepage for the flow focusing 20 case only, comparing the seepage percentage for the thermally perturbed simulation with an ambient-seepage reference case where no heat is considered.

In Figure 10, no ambient seepage occurs during the present-day climate period (which has an assumed percolation rate of $120 \mathrm{~mm} / \mathrm{yr}$ in the layer of locally focused flux for this flow focusing 20 case, see Table 3). However, during the monsoon and glacial climate scenarios, the capillary barrier is overcome (no contribution from evaporation in the ambient cases) and seepage percentages of $6 \%$ (320 mm/yr) and 16\% (500 mm/yr) are achieved (a seepage percentage of $16 \%$ means that $16 \%$ of the percolation water arriving at the drift wall is seeping into the drift). Although ambient seepage does occur in the monsoon climate, thermal seepage is not present until the glacial climate infiltration rate is reached. As expected, the start of seepage corresponds to the fracture saturations reaching their threshold values. At the year 2000, we see the result for the no convective mixing case (dashed-dotted line) jumps immediately to a $2 \%$ seepage percentage, and increases from this time on, eventually reaching about $8 \%$ of the percolation rate.

Similarly, seepage starts around 2100 years after waste emplacement in the moderate convective mixing case (solid line), but always remains slightly below the seepage percent in the no convective mixing case. This is because even moderate convective 
mixing allows for some removal of moisture from the drift walls and thereby reduces the rate of seepage. In the strong convective mixing case (dashed line), seepage is substantially decreased and starts later, around 3200 years after emplacement—well past the thermal pulse with temperatures around $60^{\circ} \mathrm{C}$. At year 5000, with a seepage percentage of only 3.5\%, the strong convective mixing case has significantly lower values than the $7 \%$ and $8 \%$ observed in the moderate and no convective mixing cases. As suggested earlier, these results show that strong convective mixing due to natural convection can reduce seepage significantly for the time period that thermal perturbation is present.

\section{CONCLUSIONS}

We conducted a numerical study to explore the impact that natural convection processes have on the reduction of drift seepage at the Yucca Mountain repository. We developed a new TOUGH2 seepage model based off of existing seepage models and employed results from a previous natural convection model. This natural convection model, coupled to existing modeling approaches for predicting heat and mass transport in the rock mass, approximates in-drift convection as a binary diffusion process.

We performed quasi three-dimensional simulations runs for a detailed geometrical representation of an emplacement drift cross-section plus surrounding fractured rock located in one of the southern panels of the repository. Three simulation cases represent different degrees of convective mixing in drifts as determined from CFD studies reported in the literature along with three different flow focusing cases to capture the effect of 
preferential flow caused by subsurface heterogeneity. Our simulation results demonstrate the importance of in-drift natural convection on seepage reduction. Strong convective mixing in natural convection:

- causes considerable delay in the rewetting of the fracture rock, and also the seepage, in all flow focusing cases.

- reduces the maximum fracture saturations achieved at the drift wall.

- significantly reduces the amount of seepage into the drift when compared to the other convective mixing cases.

Natural convection effects thus should improve the performance of the repository, since smaller relative humidity values, with reduced local seepage, form a more desirable waste package environment. Since the results of our study have demonstrated the potential importance of natural convection in assessing the future $\mathrm{TH}$ conditions in Yucca Mountain drifts, we recommend conducting large-scale field experiments in heated open tunnel sections to (1) validate several model assumptions and (2) to better constrain the uncertain magnitude of natural convection occurring in such tunnels (i.e., to determine whether natural convection effects in heated drifts at Yucca Mountain would be better described by the moderate or by the strong convective mixing modeling scenarios). 


\section{ACKNOWLEDGMENTS}

This work was supported by the Director, Office of Civilian Radioactive Waste Management, Office of Science and Technology and International, of the U.S. Department of Energy, under Contract No. DE-AC02-05CH11231. Many thanks for the input and assistance with the development of the parallelized version of TOUGH2 goes to Dr. Keni Zhang of Lawrence Berkeley National Laboratory. Without his contributions, this study would not have been possible. We are also grateful to Liange Zheng of Lawrence Berkeley National Laboratory and to the two anonymous reviewers for their insightful and constructive comments. 


\section{FIGURES}

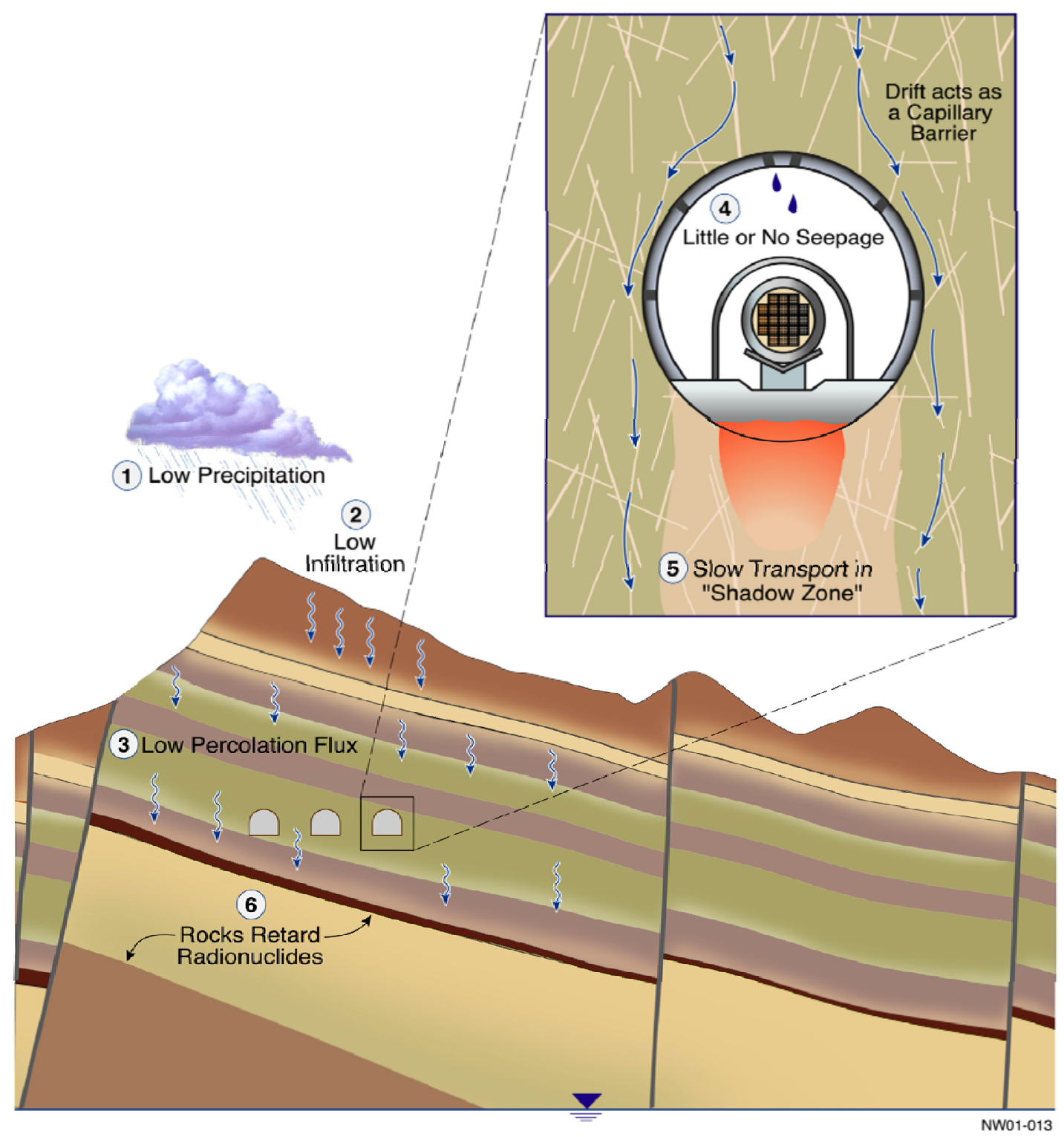

Figure 1. Schematic of percolation and seepage in the Yucca Mountain repository and around the drift. 


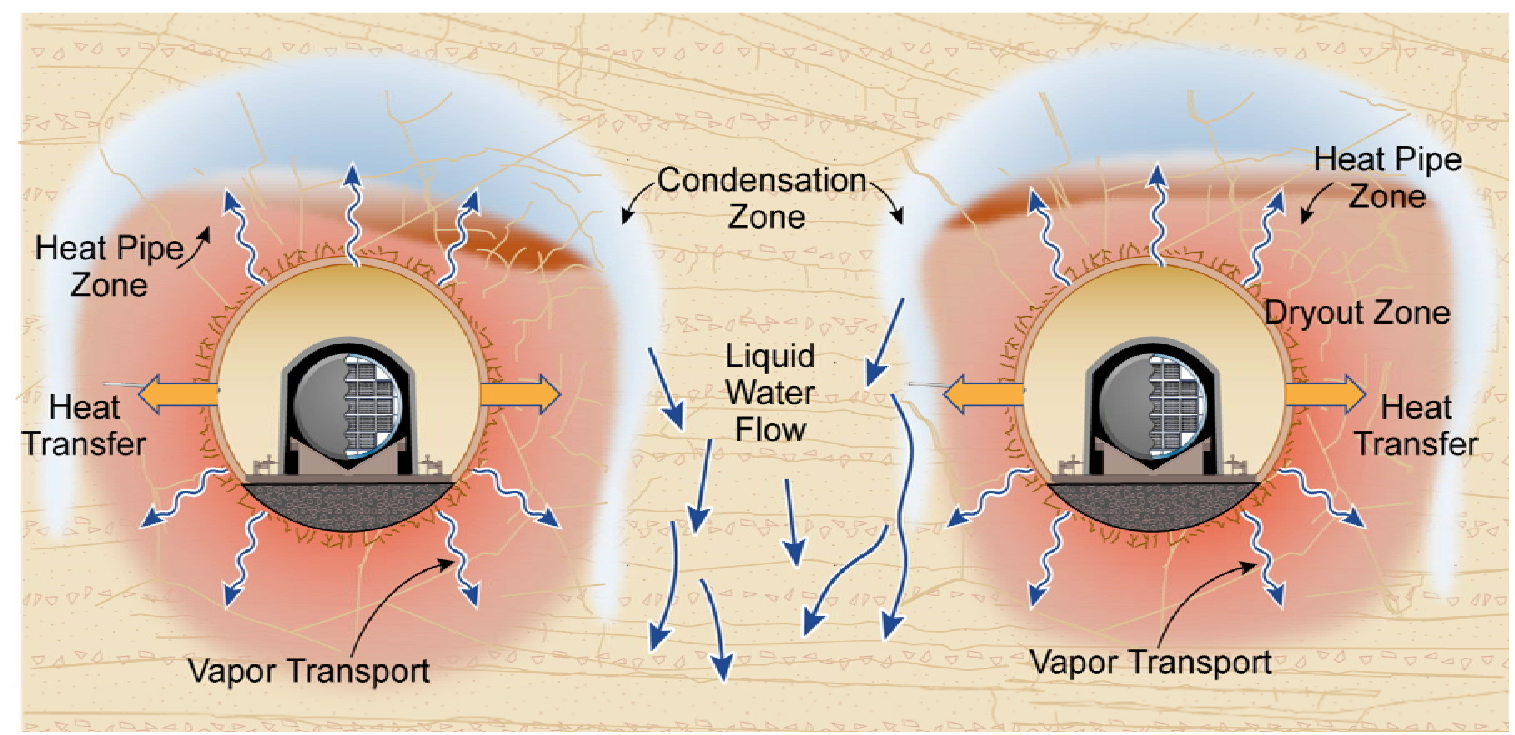

Figure 2. Thermal-hydrologic processes near two adjacent drifts during boiling phase of emplacement ${ }^{13}$. (Distance between drifts not to scale). 

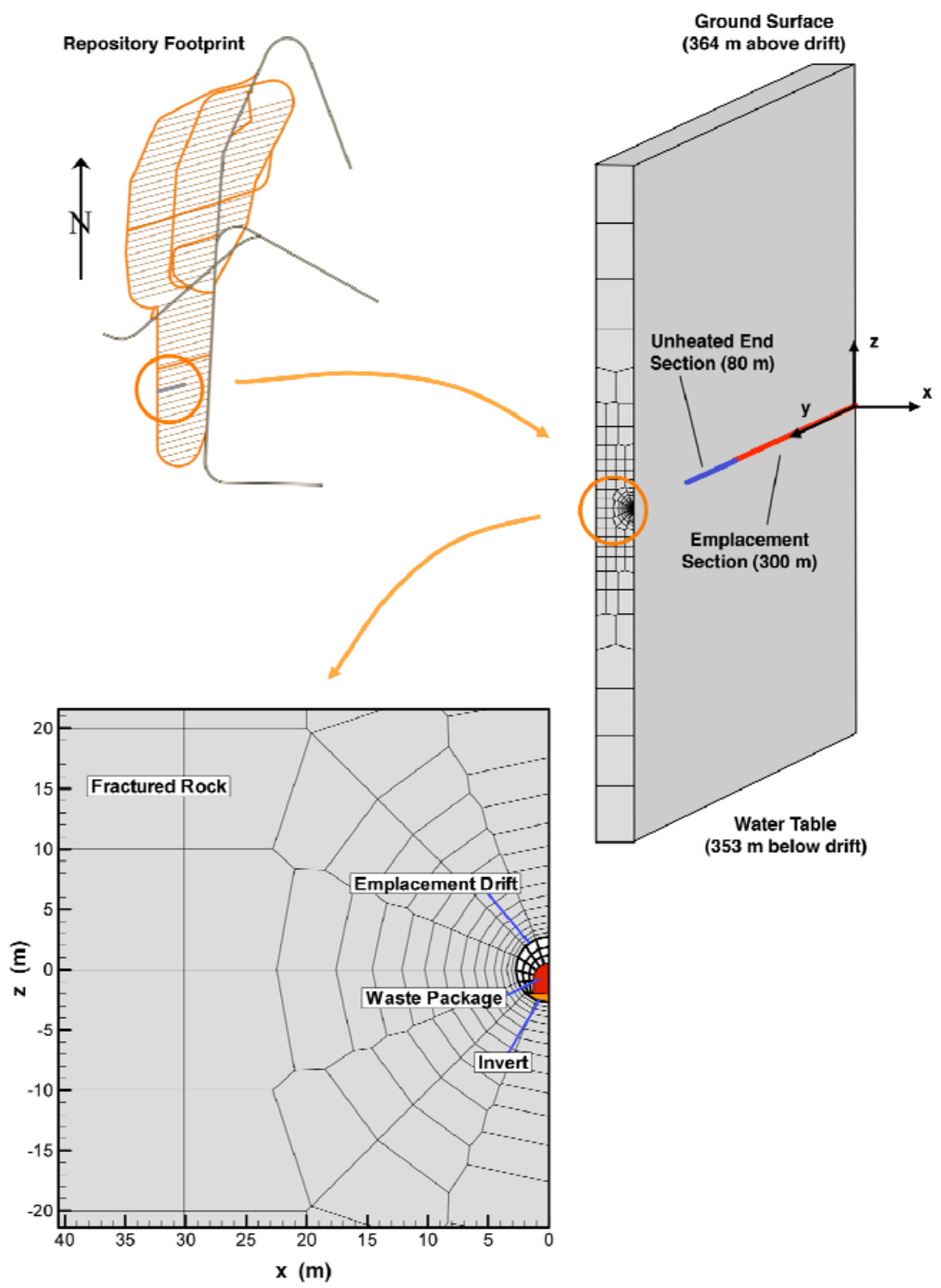

Figure 3. Schematic showing the geometry of the three-dimensional model domain (not to scale). Close-up view shows discretization of drift and drift vicinity. 


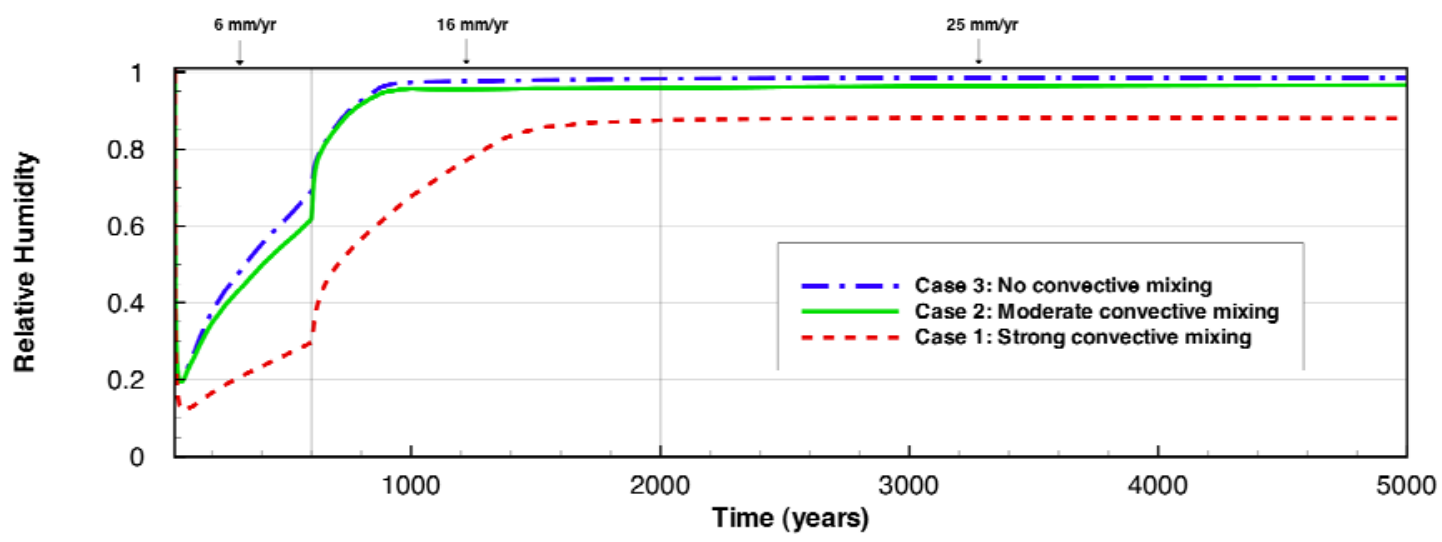

Figure 4. Evolution of relative humidity (RH) of in-drift element at the drift center in the full-drift \& rock natural convection model (nat-co) for all three convective mixing cases. Vertical grey lines indicate stepwise changes in percolation flux caused by expected future climate changes at 600 years and 2000 years after emplacement. 

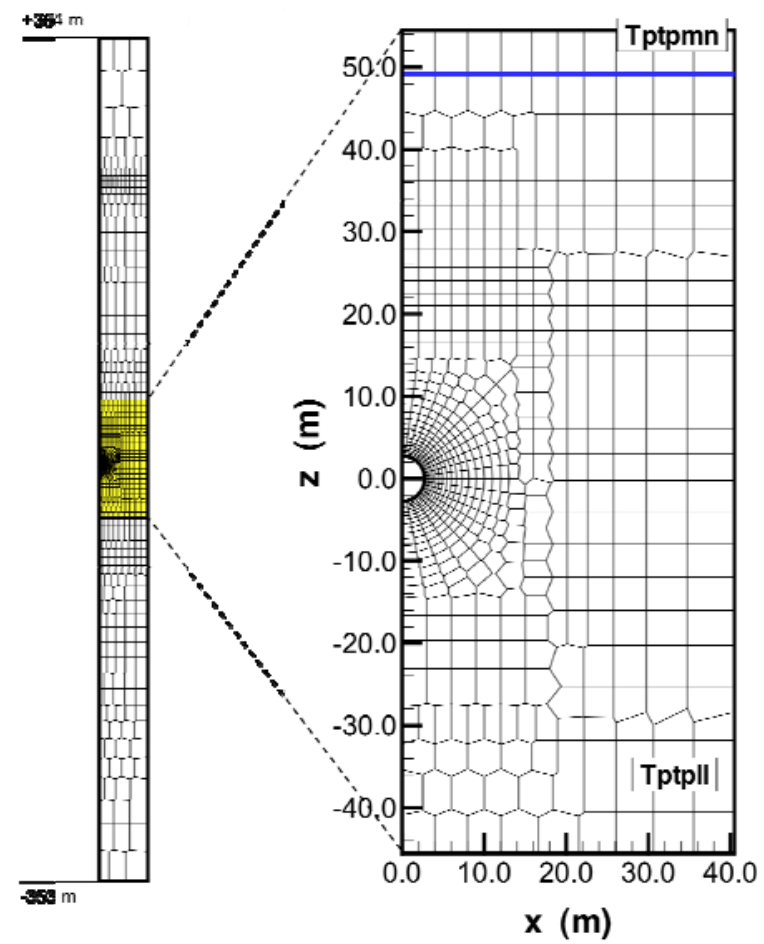

a) X-Z plane view of grid discretization

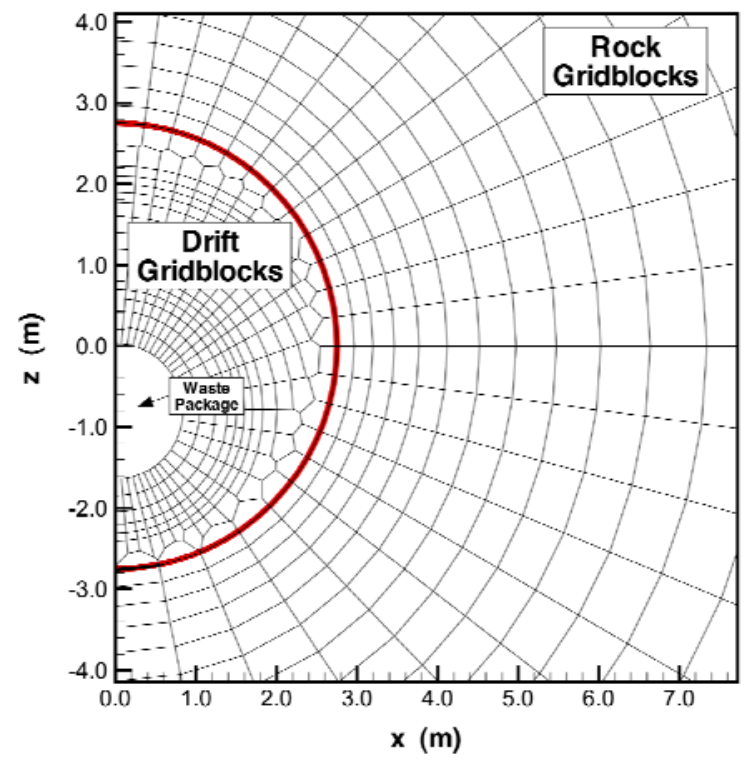

b) Detailed X-Z plane view of in-drift and surrounding rock discretization (thick line shows drift wall boundary).

Figure 5. X-Z plane view of grid discretization. 


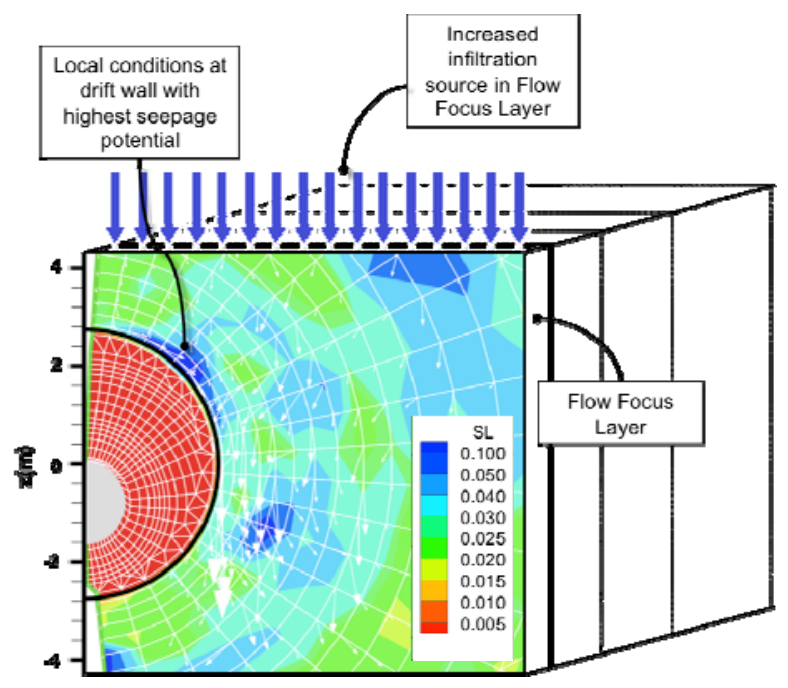

Figure 6. A sample contour plot of the fracture saturation in the drift vicinity displaying increased saturations (dark regions) due to heterogeneity in fracture permeability. Arrow field represents magnitude of percolation flow around the rock surrounding the drift. 


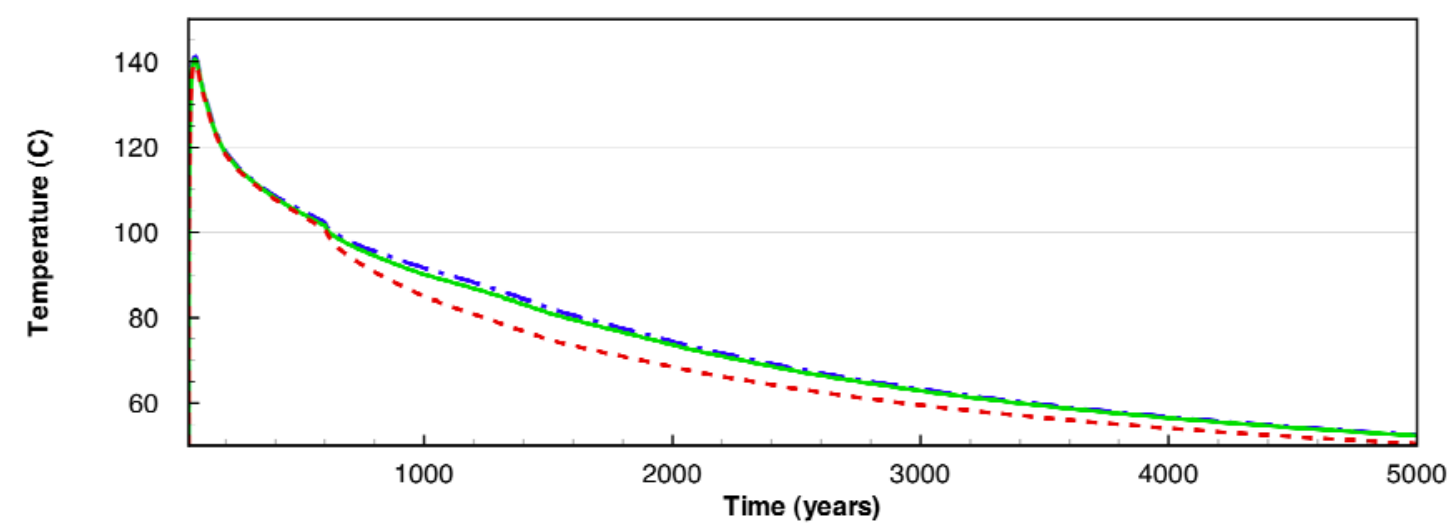

a) No flow focusing case

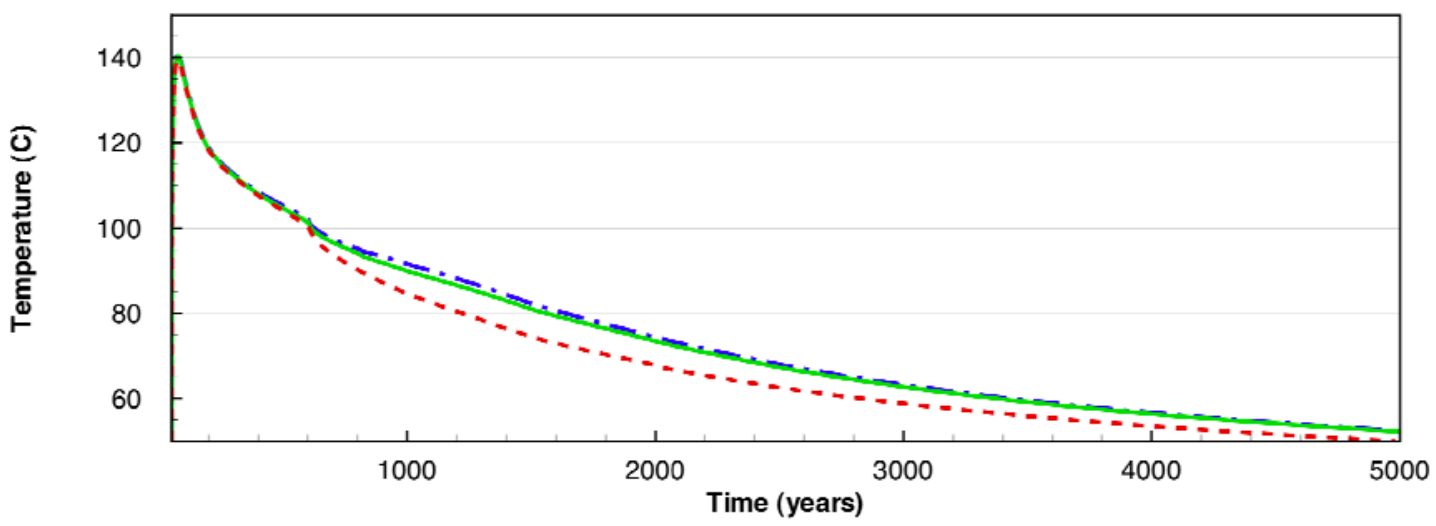

b) Flow focusing 10 case

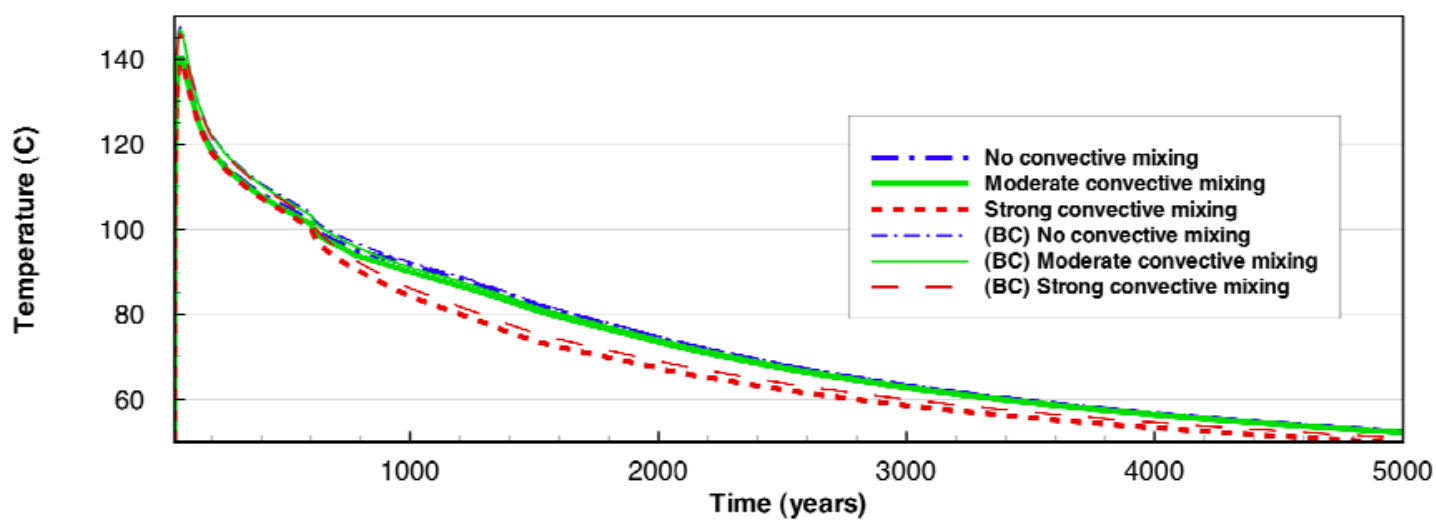

c) Flow focusing 20 case.

Figure 7. Temperature evolution in seepage-prone element at drift wall (solid line) and boundary source (dashed line) for (a) no flow focusing, (b) flow focusing 10, and (c) flow focusing 20 cases. 


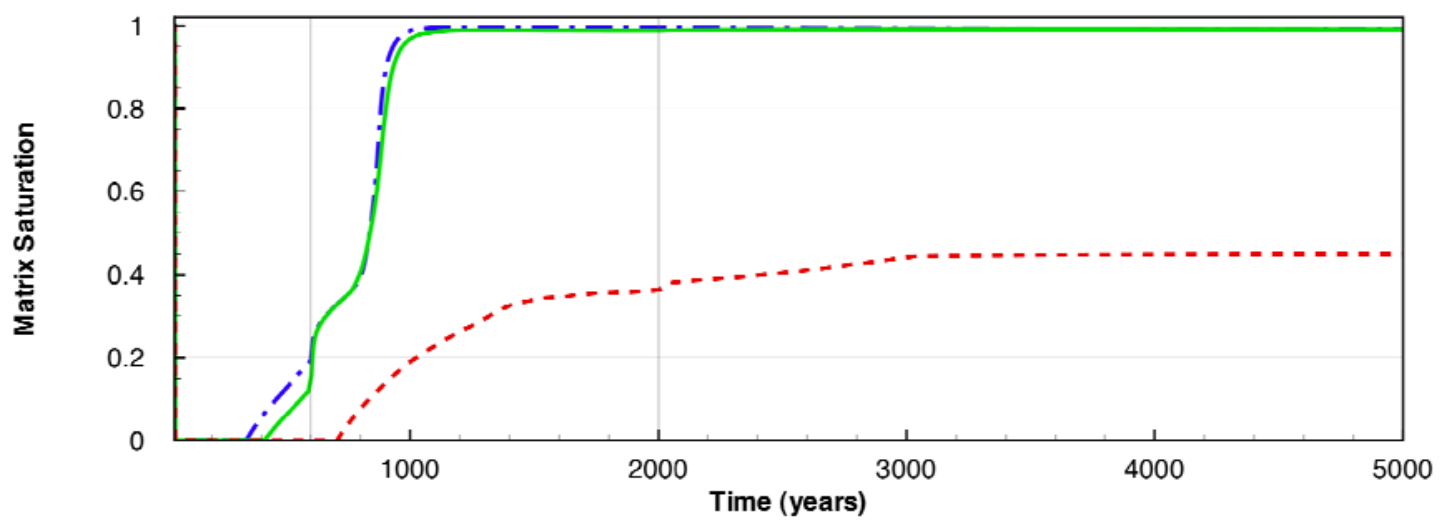

a) No flow focusing case.

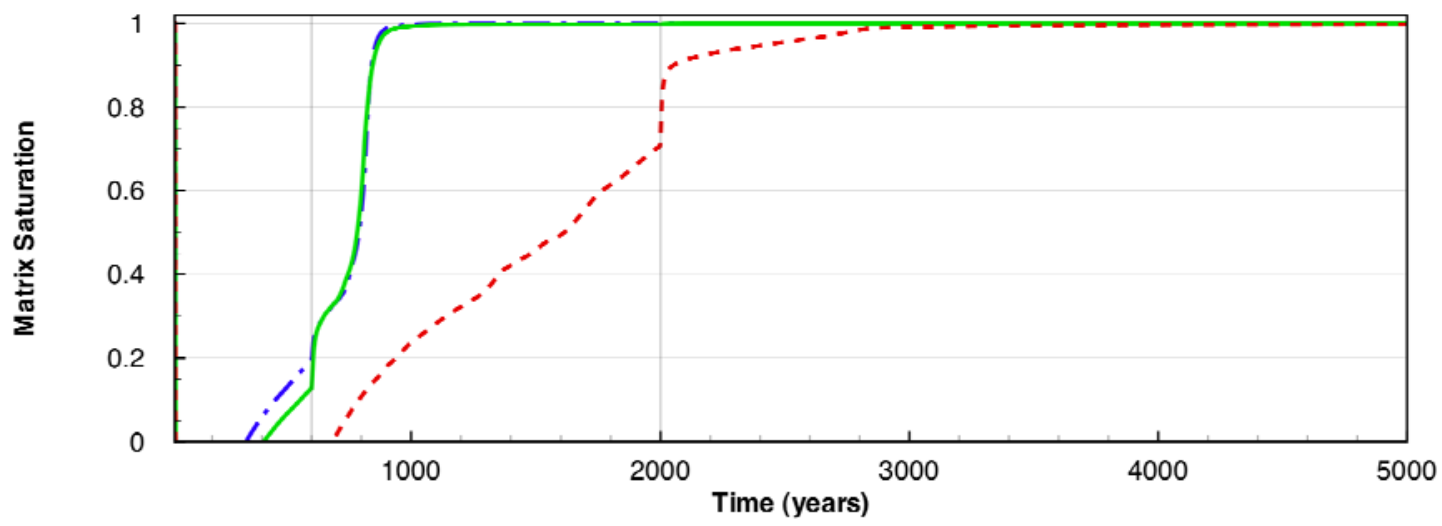

b) Flow focusing 10 case.

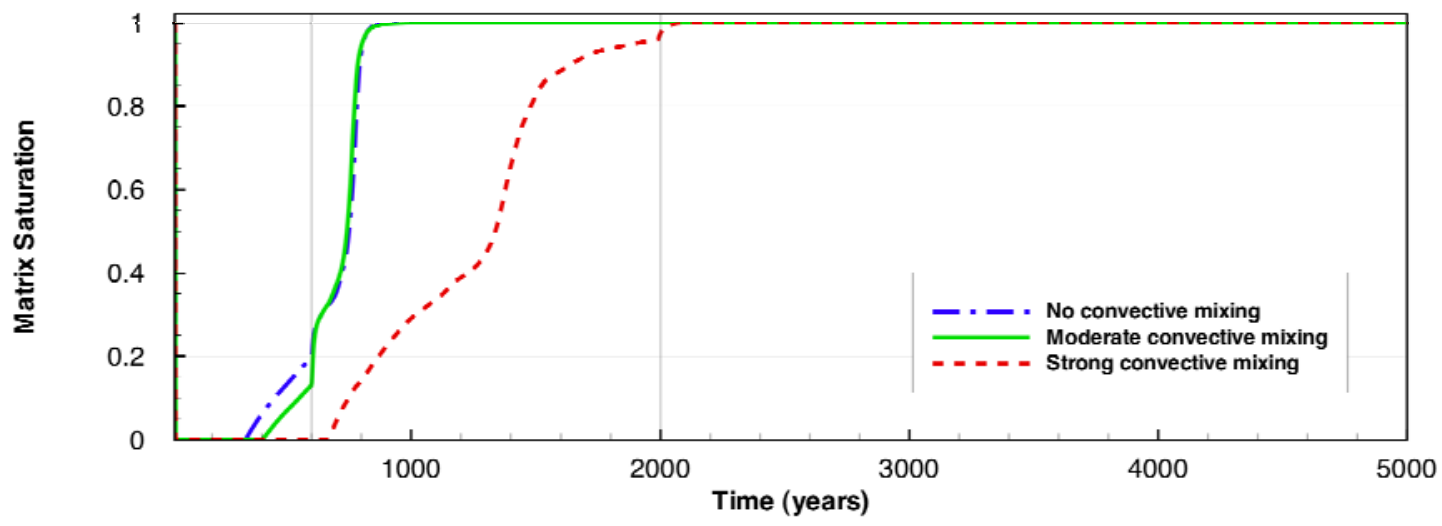

c) Flow focusing 20 case.

Figure 8. Matrix saturation in a seepage prone element at the drift wall for (a) no flow focusing, (b) flow focusing 10, and (c) flow focusing 20 cases. Vertical grey lines indicate stepwise changes in percolation flux caused by expected future climate changes at 600 years and 2000 years after emplacement. 


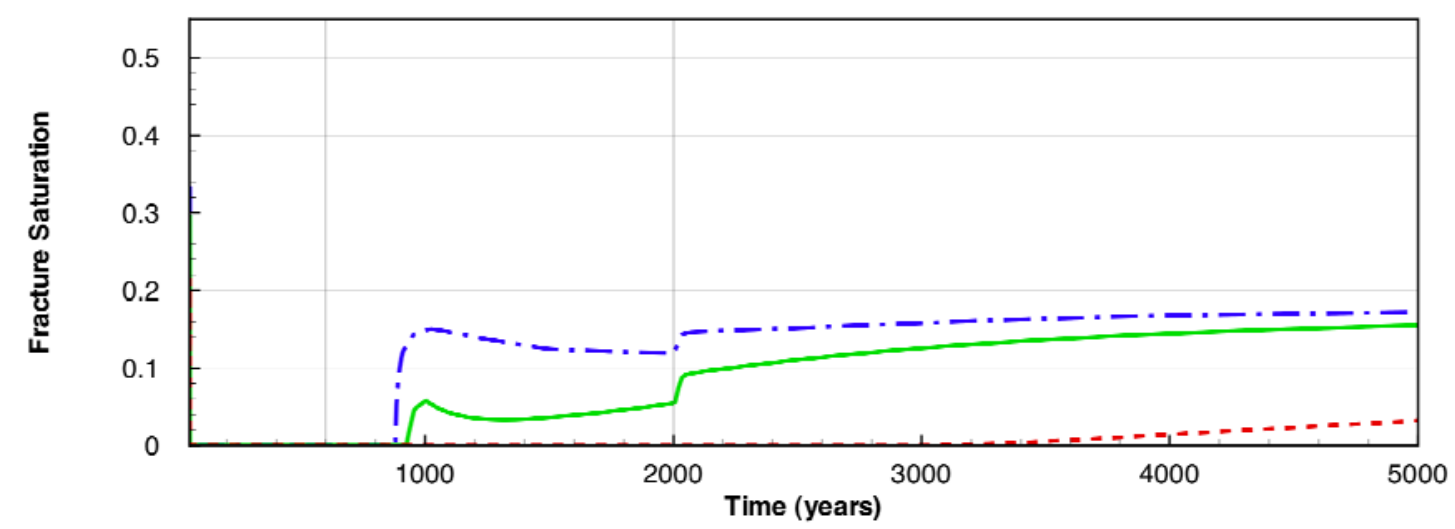

a) No flow focusing case.

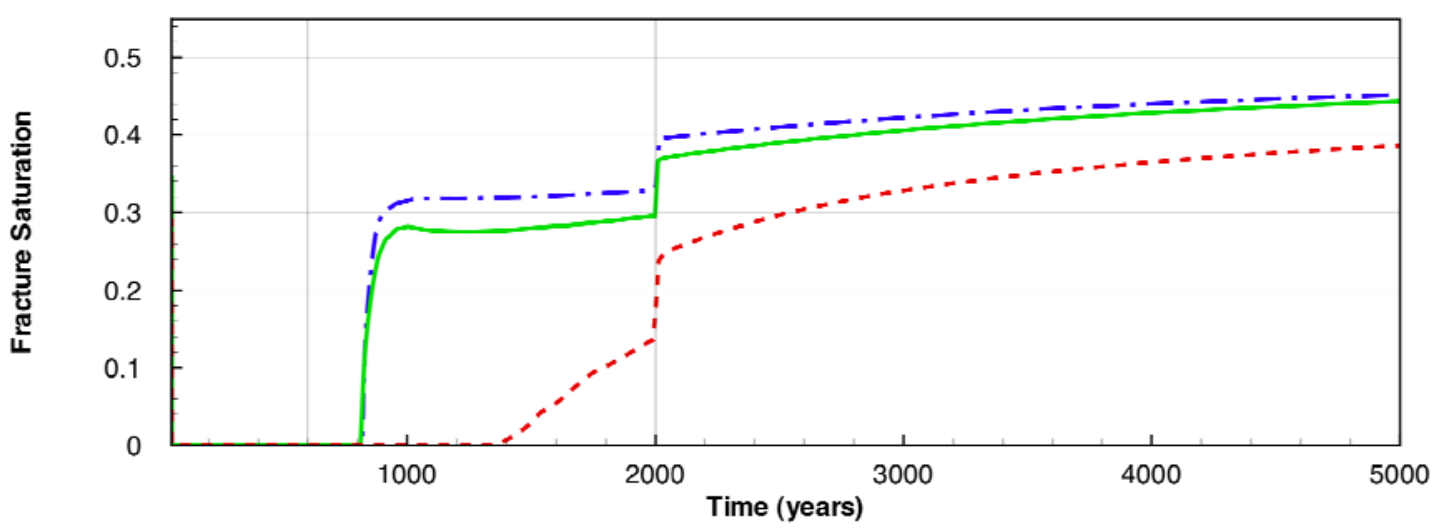

b) Flow focusing 10 case.

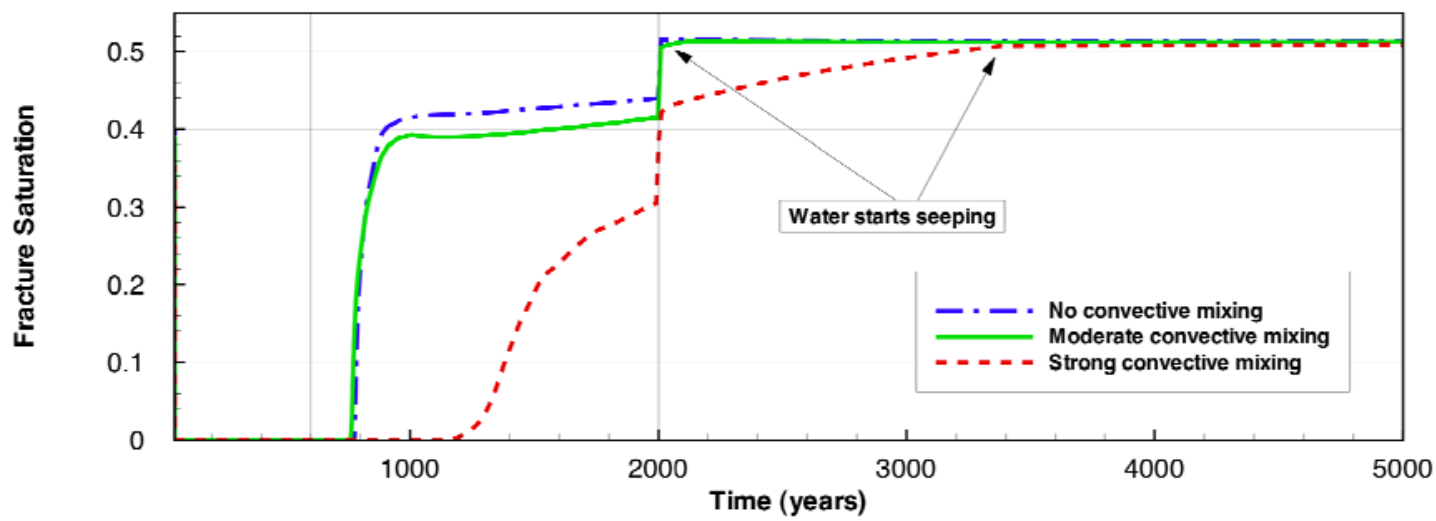

c) Flow focusing 20 case.

Figure 9. Fracture saturation in a seepage prone element at the drift wall for (a) no flow focusing, (b) flow focusing 10, and (c) flow focusing 20 cases. Vertical grey lines indicate 
stepwise changes in percolation flux caused by expected future climate changes at 600 years and 2000 years after emplacement. 


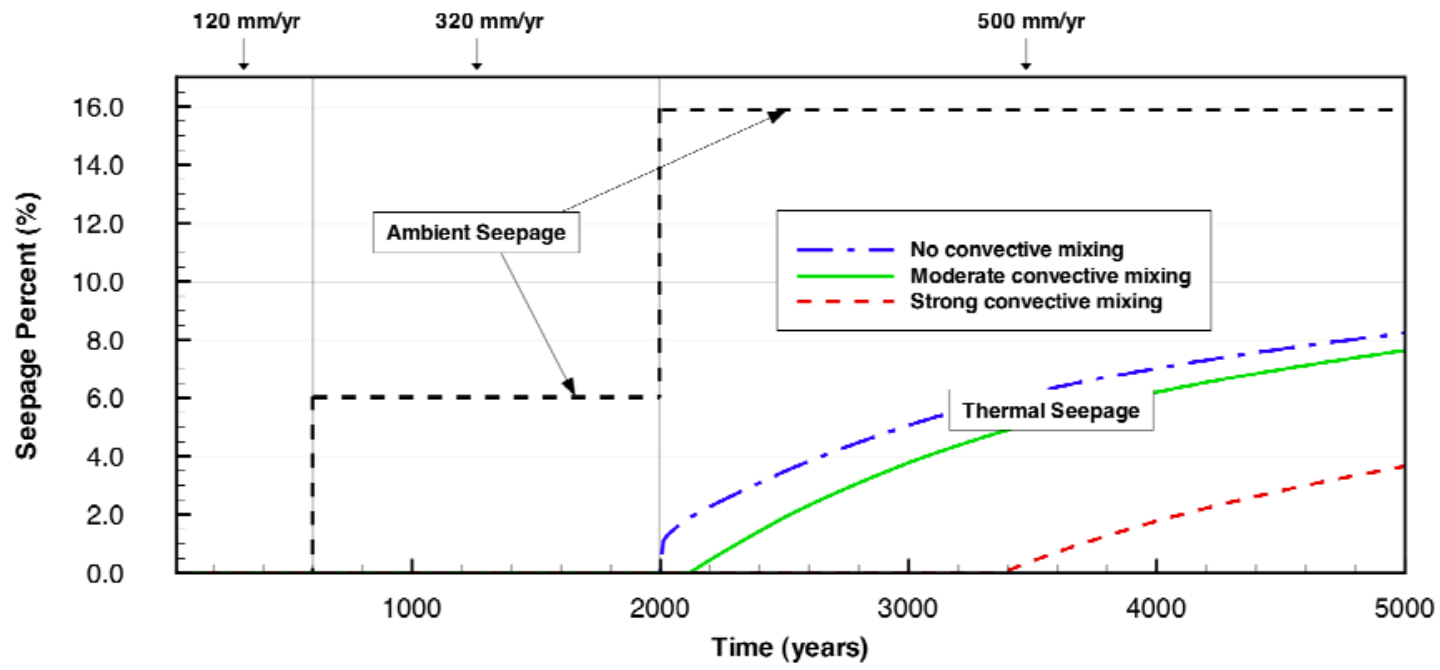

Figure 10. Seepage percentage for the flow focusing 20 case for both ambient (dashed lines) and thermal (solid lines) seepage. (No seepage is observed in either the flow focusing 10 or the no flow focusing cases). 


\section{TABLES}

Table 1. Effective mass dispersion coefficients prescribed in nat-co model.

\begin{tabular}{lc}
\hline Case & $\begin{array}{c}\text { Dispersion } \\
\text { Coefficient } \\
\left(\mathrm{m}^{2} / \mathrm{s}\right)\end{array}$ \\
\hline $\begin{array}{l}\text { Case 1: } \\
\text { Strong convective mixing }\end{array}$ & 0.1 \\
\hline $\begin{array}{l}\text { Case 2: } \\
\text { Moderate convective } \\
\text { mixing }\end{array}$ & 0.004 \\
\hline $\begin{array}{l}\text { Case 3: } \\
\text { No convective mixing }\end{array}$ & $2.14 \mathrm{E}-05$ \\
\hline
\end{tabular}


Table 2. Summary of hydrogeological and thermal input values of fractured rock mass.

\begin{tabular}{lccc}
\hline Parameter & Units & Matrix properties & Fracture properties \\
\hline Permeability & $\mathrm{m}^{2}$ & $4.48 \times 10^{-18}$ & $9.10 \times 10^{-13}$ \\
Permeability (wall layer) & $\mathrm{m}^{2}$ & $4.5 \times 10^{-15}$ & - \\
Porosity & - & 0.1486 & $9.6 \times 10^{-3}$ \\
Rock grain density & $\mathrm{kg} / \mathrm{m}^{3}$ & 2325 & - \\
Rock grain specific heat & $\mathrm{J} / \mathrm{kg} K$ & 985 & - \\
Dry thermal conductivity & $W / m K$ & 1.278 & - \\
Wet thermal conductivity & $W / m K$ & 1.890 & - \\
Tortuosity & - & 0.20 & - \\
Capillary-strength parameter, $\alpha$ & $P a$ & $9.26 \times 10^{4}$ & $9.71 \times 10^{3}$ \\
Capillary-strength parameter for & $P a$ & - & 589 \\
fractures in drift vicinity, $\alpha$ & & & \\
van Genuchten parameter, $m$ & - & 0.216 & 0.633 \\
Residual liquid saturation & - & 0.12 & 0.01 \\
\hline
\end{tabular}

Fracture-Matrix geometry properties

\begin{tabular}{|c|c|c|}
\hline Volume Fraction of Fractures & - & 0.0097 \\
\hline Fracture-Matrix interface area & $\mathrm{m}^{2} / \mathrm{m}^{3}$ & 9.8 \\
\hline $\begin{array}{l}\text { Representative distance between } \\
\text { fracture and matrix blocks }\end{array}$ & $m$ & 0.0528 \\
\hline
\end{tabular}


Table 3. Flow focusing cases and corresponding percolation fluxes.

\begin{tabular}{l|ccc}
\multirow{2}{*}{} & \multicolumn{3}{|c}{$\begin{array}{c}\text { Percolation rate in layer of locally focused flux } \\
\text { (for the three climate scenarios) } \\
\text { [mm/yr] }\end{array}$} \\
\cline { 2 - 4 } Cases & $\begin{array}{c}\text { Modern } \\
\text { (0-600 years) }\end{array}$ & $\begin{array}{c}\text { Monsoon } \\
(600-2000 \text { years) }\end{array}$ & $\begin{array}{c}\text { Glacial } \\
\text { ( }>2000 \text { years })\end{array}$ \\
\hline No Flow Focusing & 6.0 & 16.0 & 25.0 \\
Flow Focusing 10 & 60.0 & 160.0 & 250.0 \\
Flow focusing 20 & 120.0 & 320.0 & 500.0 \\
\hline
\end{tabular}




\section{REFERENCES}

1. Pruess, K., Oldenburg, C., \& Moridis, G. (1999) TOUGH2 User's Guide, version 2.0., Report LBNL-43134, Lawrence Berkeley Nat. Lab, Berkeley, CA.

2. Birkholzer, J. T., Mukhopadhyay, S., \& Tsang, Y. W. (2004) Modeling Seepage Into Heated Waste Emplacement Tunnels in Unsaturated Fractured rock, Soil Sci Soc America, Vadose Zone Journal, Vol. 3, pp. 819-836.

3. Webb, S. W. \& Reed, A. (2004) In-Drift Natural Convection and Condensation, MDL-EBS-MD- 000001 REV 00, Yucca Mountain Project Report, Bechtel SAIC Company, Las Vegas, Nevada.

4. Birkholzer, J., Webb, S., Halecky, N., Peterson, P., \& Bodvarsson, G. (2006) Evaluating the Moisture Conditions in the Fractured Rock at Yucca Mountain: The Impact of Natural Convection Processes in Heated Emplacement Drifts, Soil Sci Soc America, Vadose Zone Journal, Vol. 5, pp. 1172-1193.

5. Birkholzer, J., Halecky, N., Webb, S., Peterson, P., \& Bodvarsson, G. (2008) A Modeling Study Evaluating the Thermal-Hydrological Conditions in and near Waste Emplacement Drifts at Yucca Mountain, American Nuclear Society, Nuclear Technology, Vol 63(1), pp. 147-164.

6. Flint, A. L., Flint, L. E., Bodvarsson, G. S., Kwicklis, E. M., \& Fabryka-Martin, J. (2001) Evolution of the conceptual model of unsaturated zone hydrology at Yucca Mountain, Nevada, Journal of Hydrology, Vol. 247, pp. 1-30.

7. Wu, Y. S., Pan, L., Zhang, W., \& Bodvarsson, G. (2002) Characterization of flow and transport processes within the unsaturated zone of Yucca Mountain, Nevada, under 
current and future climates, Journal of Contaminant Hydrology, Vol. 54, pp. 215247.

8. Birkholzer, J., Li, G., Tsang, C. F., \& Tsang, Y. (1999) Modeling studies and analysis of seepage into drifts at Yucca Mountain, Journal of Contaminant Hydrology, Vol. 38(1-3), pp. 349-384.

9. Spycher, N., Sonnenthal, E., \& Apps, J. (2003) Fluid Flow and Reactive Transport around Potential Nuclear Waste Emplacement Tunnels at Yucca Mountain, Nevada, Journal of Contaminant Hydrology, Vol. 62-63, pp. 653-673.

10. Raithby, G. \& Hollands, K. (1985) Handbook of Heat Transfer Fundamentals, McGraw-Hill Book Company, New York.

11. Birkholzer, J., Halecky, N., Webb, S., Peterson, P., \& Bodvarsson, G. (2006) The Impact of Natural Convection on Near-Field TH Processes at Yucca Mountain, Proceedings, 11th International High-Level Nuclear Waste Conference, Las Vegas, NV.

12. Webb, S. \& Itamura, M. (2004) Calculation of Post-closure natural convection heat and mass transfer in Yucca Mountain Drifts, Proceedings of HTFED04 2004 ASME Heat Transfer/Fluids Engineering Summer Conference, American Society of Mechanical Engineers, Charlotte, NC, USA.

13. Birkholzer, J. T., Mukhopadhyay, S., \& Tsang, Y. W. (2004) Drift-Scale Coupled Processes (DST and TH Seepage) Models, MDL-NBS-HS-000015 REV 01, Yucca Mountain Project Report, Bechtel SAIC Company, Las Vegas, Nevada. 
14. Vogt, T. (2004) Geologic Framework Model (GFM2000), MDL-NBS-GS-000002, REV 02, Yucca Mountain Project Report, Bechtel SAIC Company, Las Vegas, Nevada.

15. Zhang, K., Wu, Y. S., \& Bodvarsson, G. (2003) Parallel Computing Simulation of Fluid Flow in the Unsaturated Zone of Yucca Mountain, Nevada, Journal of Contaminant Hydrology, Vol. 62, pp. 381-399.

16. Finsterle, S., Ahlers, C.F., Trautz, R.C., \& Cook, P.J. (2003) Inverse and Predictive Modeling of Seepage into Underground Openings, Journal of Contaminant Hydrology, Vol. 62-63, pp. 89-109.

17. Ghezzehei, T., Trautz, R., Finsterle, S., Cook, P., \& Ahlers, C. (2004) Modeling Coupled Evaporation and Seepage in Ventilated Cavities, Soil Sci Soc America, Vadose Zone Journal, Vol. 3, pp. 806-818. 


\section{DISCLAIMER}

This document was prepared as an account of work sponsored by the United States Government. While this document is believed to contain correct information, neither the United States Government nor any agency thereof, nor The Regents of the University of California, nor any of their employees, makes any warranty, express or implied, or assumes any legal responsibility for the accuracy, completeness, or usefulness of any information, apparatus, product, or process disclosed, or represents that its use would not infringe privately owned rights. Reference herein to any specific commercial product, process, or service by its trade name, trademark, manufacturer, or otherwise, does not necessarily constitute or imply its endorsement, recommendation, or favoring by the United States Government or any agency thereof, or The Regents of the University of California. The views and opinions of authors expressed herein do not necessarily state or reflect those of the United States Government or any agency thereof or The Regents of the University of California.

Ernest Orlando Lawrence Berkeley National Laboratory is an equal opportunity employer. 